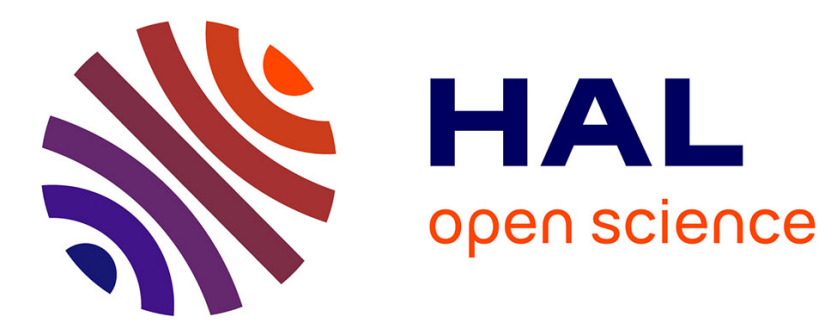

\title{
El saber del escritor. Por una teoría de la cita
}

Federico Bravo

\section{To cite this version:}

Federico Bravo. El saber del escritor. Por una teoría de la cita. Bulletin Hispanique, 1995, 97 (1), pp.361-374. 10.3406/hispa.1995.4871 . halshs-02062553

\section{HAL Id: halshs-02062553 \\ https://shs.hal.science/halshs-02062553}

Submitted on 9 Mar 2019

HAL is a multi-disciplinary open access archive for the deposit and dissemination of scientific research documents, whether they are published or not. The documents may come from teaching and research institutions in France or abroad, or from public or private research centers.
L'archive ouverte pluridisciplinaire $\mathbf{H A L}$, est destinée au dépôt et à la diffusion de documents scientifiques de niveau recherche, publiés ou non, émanant des établissements d'enseignement et de recherche français ou étrangers, des laboratoires publics ou privés. 


\section{El saber del escritor. Por una teoría de la cita} Federico Bravo

\section{Citer ce document / Cite this document :}

Bravo Federico. El saber del escritor. Por una teoría de la cita. In: Bulletin Hispanique, tome 97, n¹, 1995. pp. 361-374; doi : https://doi.org/10.3406/hispa.1995.4871

https://www.persee.fr/doc/hispa_0007-4640_1995_num_97_1_4871

Fichier pdf généré le 08/05/2018 


\title{
Résumé
}

Le savoir " littéraire " de l'écrivain étant, comme son savoir " linguistique », structuré comme un diagramme, le phénomène intertextuel est analysé ici sous un double rapport, à la fois comme mécanisme induit (conditionné par le diagramme) et comme mécanisme inducteur Gui-même conditionnant de récriture). Un sonnet de Quevedo, où l'auteur, explorant en même temps le savoir de l'écrivain et l'écriture de ce savoir, élabore une véritable poétique de la citation, sert à illustrer la réflexion théorique.

\section{Resumen}

Partiendo del principio de que el saber « literario » del escritor está, del mismo modo que su saber « lingüístico », estructurado como un diagrama, el presente artículo explora el fenómeno intertextual bajo su doble vertiente, en tanto que mecanismo inducido (condicionado por el diagrama) y como mecanismo inductor (condicionador a su vez de la escritura). Un soneto de Quevedo, en que el autor, sondeando a la vez el saber del escritor y la escritura de ese saber, elabora una verdadera poética de la cita, ilustra la reflexión teórica.

\begin{abstract}
Assuming that the "literary " knowledge of the writer is, as well as his "linguistic » knowledge, organized like a, diagram, this paper explores the intertextual phenomenon both as an inducted mechanism (conditioned by the diagram) and as inductor mechanism (conditioning the writing). A sonnet of Quevedo, in which the author, by exploring both the knowledge of the writer and the writing of this knowledge, élaborâtes a true poetics of quotation, ilustrates the theoretical reflexion.
\end{abstract}




\title{
EL SABER DEL ESCRITOR Por una teoría de la cita
}

\author{
Federico BRAVO* \\ ...siendo vos de vos propia, en el espejo, \\ original, pintor, pincel y copia. \\ QUEVEDO, soneto 307.
}

\begin{abstract}
Le savoir * littéraire * de l'écrivain étant, comme son savoir * linguistique $\#$, structuré comme un diagramme, le phénomène intertextuel est analysé ici sous un double rapport, à la fois comme mécanisme induit (conditionné par le diagramme) et comme mécanisme inducteur (lui-même conditionnant de l'écriture). Un sonnet de Quevedo, où l'auteur, explorant en même temps le savoir de l'écrivain et l'écriture de ce savoir, élabore une véritable poétique de la citation, sert à illustrer la réflexion théorique.

Partiendo del principio de que el saber « literario * del escritor está, del mismo modo que su saber * lingứístico $\%$, estructurado como un diagrama, el presente artículo explora el fenómeno intertextual bajo su doble vertiente, en tanto que mecanismo inducido (condicionado por el diagrama) y como mecanismo inductor (condicionador a su vez de la escritura). Un soneto de Quevedo, en que el autor, sondeando a la vez el saber del escritor y la escritura de ese saber, elabora una verdadera poética de la cita, ilustra la reflexión térica.

Assuming that the « literary » knowledge of the writer is, as well as his \& linguistic * knowledge, organized like a diagram, this paper explores the intertextual phenomenon both as an inducted mechanism (conditioned by the diagram) and as inductor mechanism (conditioning the writing). A sonnet of Quevedo, in which the author, by exploring both the knowledge of the writer and the writing of this knowledge, elaborates a true poetics of quotation, ilustrates the theoretical reflexion.
\end{abstract}

Mots-clés : Citation - Quevedo - Lecture - Récriture.

\footnotetext{
- Université Michel de Montaigne-Bordeaux III, Institut d'Études Ibériques, Domaine Universitaire, 33405 Talence, France.
}

B. Hi., T. $97,1995, n^{\circ} 1$, p. 361 à 374. 
Uno de los logros de la semántica y de la lexicología estructurales consiste en haber demostrado que no hay signo que no sea derivado de otro signo ni creación léxica que no sea reutilización de estructuras preexistentes. La noción de modelo lexicogénico, a la vez que acaba con el concepto - vigente durante años en semántica histórica - de contingencia, relativiza y supera el concepto de innovación lingüística, puesto que toda innovación está inscrita de alguna manera en la memoria del propio signo. De este modo, por ejemplo, Pierre Guiraud pondrá en tela de juicio la metáfora del ajedrez empleada por Ferdinand de Saussure quien, como es sabido, asimilaba la lengua a las piezas y a las reglas del juego y el habla al desarrollo de la partida. En efecto, lo que Saussure olvidaba en su célebre ejemplo era " la memoria de las jugadas ya realizadas. Un manual de ajedrez es un repertorio de combinaciones anteriormente hechas y vueltas a utilizar en cada partida. Análogamente, el diccionario y la gramática de una lengua son los inventarios de las jugadas realizadas por los hablantes ${ }^{1}$ ".

Lo que vale para la palabra y para el léxico vale también para la frase y, más allá, para el discurso en general, sea literario o no. Hablar no es otra cosa que activar o, mejor, reactivar la memoria de las jugadas realizadas en el discurso ; del mismo modo componer un soneto, por ejemplo, es imponerle a la escritura un modelo $y$, por lo mismo, citar cuantas escrituras lo han hecho suyo a su vez. Contrariamente a la idea preconcebida según la cual el uso precede a la mención, es el acto de mención el que, tanto en la ontogénesis de la palabra como en la adquisición del lenguaje, precede al acto lingüístico puramente instrumental : el niño aprende a citar antes de aprender a hablar y sólo accede al lenguaje por mediación del metalenguaje. El hablante no empieza a producir hasta que deja de tener conciencia de estar reproduciendo : el uso no es, en última instancia, sino un acto de mención olvidado.

La creación, por más que los diccionarios la definan como el acto de sacar de la nada, nace por tanto del encuentro de una escritura con un modelo a un tiempo afirmado y negado, pero siempre en constante interacción con ella. Ni siquiera el mito, que es una reescritura ya tardía o, si se prefiere, la " traducción original ${ }^{2}$ " de los modelos que rigen la actividad consciente y preconsciente de la comunidad que lo ha engendrado, restituye verdaderamente a la palabra « creación » su sentido plenamente demiúrgico : Dios crea al hombre a su imagen y semejanza, es decir, según un modelo, y si, al principio, Dios creó los cielos y la tierra es porque antes del principio existía ya la palabra que había de permitir su advenimiento ${ }^{3}$.

1. Pierre Guiraud, Structures etymologiques du lexique français, Paris, Payot, 1986, p. 246. (La traducción es nuestra).

2. Tomo esta expresión del trabajo de Éliane Amado Lévy-Valensy, La dignite des mots, Paris, Les empêcheurs de tourner en rond, 1995, p. 33.

3. La narración mítica de la creación y la reflexión sobre el funcionamiento del lenguaje corren parejas desde los primeros versículos del Génesis. Ambas se imbrican de tal manera que el primer acontecimiento fundador del Antiguo Testamento puede leerse también como una formidable parábola lingüística, en que se plantean cuestiones tan diversas como el estatu to ilocutivo de los verbos 
Porque todo texto es signo y todo signo producto de una derivación, el texto no es sino re-producción de modelos que motivan la escritura y a los que la escritura remotiva a su vez. Si cada elemento del sistema se encuentra atrapado en una red de conexiones - la misma que ilustraba Saussure mediante el ejemplo de la palabra "enseñanza ", de la que extraía los diferentes paradigmas asociativos -, el texto forma parte, como significante complejo que es y con el mismo derecho que la palabra y sus formantes, del entramado diagramático que, a un tiempo, posibilita y predetermina la derivación, sea ésta verbal o textual. A partir de ahí, podría concebirse, pues, un tipo de aproximación a las prácticas citacionales basado en el modelo asociativo definido por Saussure. Pero para ello habría que empezar reconociendo el mismo poder asociativo a las combinaciones sintagmáticas y discursivas que a cada uno de sus constituyentes y habría que extender el radio de acción de la analogía y de la connotación semiótica - que Saussure limitaba a la palabra - al sintagma, a la frase y al discurso en su totalidad. La extensión que propongo aquí podría dar cuenta así del fenómeno intertextual en su doble vertiente, como estructura textual inducida, esto es, condicionada por el diagrama, y como estructura textual inductora, es decir, condicionadora de la escritura.

A veces deliberada, a menudo involuntaria, la cita es también objeto de la reflexión teórica del escritor quien, como hace Quevedo en su soneto Desde la torre, puede convertirla en el centro mismo de su discurso. Tradicionalmente considerado como un elogio del libro, el texto, que tanto como el saber del escritor sondea la escritura de ese saber, elabora en catorce versos toda una poética de la cita. La lectura de este soneto servirá de hilo conductor a las observaciones que haré aquí sobre el fenómeno intertextual.

Retirado en la paz de estos desiertos, con pocos, pero doctos libros juntos, vivo en conversación con los difuntos y escucho con mis ojos a los muertos.

Si no siempre entendidos, siempre abiertos, o enmiendan, o fecundan mis asuntos ; y en músicos callados contrapuntos al sueño de la vida hablan despiertos.

Las grandes almas que la muerte ausenta, de injurias de los años, vengadora, libra, $;$ oh gran don Iosef !, docta la emprenta.

En fuga irrevocable huye la hora ; pero aquélla el mejor cálculo cuentat que en la lección y estudios nos mejora ${ }^{5}$.

performativos (fiat lux), el problema lógico-lingüístico de la presuposición (al principio, Dios creó los cielos y la tierra : de acuerdo, pero $i$ al principio de qué ? y $i$ al cabo de qué ?) o el de las oposiciones binarias según el esquema « término marcado / término no marcado * (a imagen - si consideramos, por ejemplo, el problema del género gramatical - de la primera mujer, fruto de la decantación de un neutro original, representado por la figura andrógina del primer Adán).

4. Cuento en la edición de R. M. Price, An anthology of Queoedo's poetry, Manchester University Press, 1966, p. 44. Se trata, sin lugar a dudas, de una errata.

5. Edición de José Manuel Blecua, Obras completas, I. Poesta original, Barcelona, Planeta, 1968, p. 105-106. 
Señalaremos para empezar que este soneto, a cuya celebridad han contribuido tanto los elogios de la crítica como las numerosas antologras poéticas que lo han reproducido, no ha sido curiosamente, hasta la fecha, sino objeto de aproximaciones parciales, con la salvedad del estudio - fundamentalmente temático - que le ha dedicado Emilio Carilla hace ya algunos años ${ }^{6}$. Curiosamente también el texto figura en las principales ediciones entre los poemas llamados " morales " de Quevedo. Es cierto que la escritura poética presenta, a partir del primer terceto, un carácter marcadamente didáctico y moral : la lectura - dice explícitamente el terceto final, jugando con la polisemia de la palabra lección, tomada aquí a la vez en el sentido de " lectura » y en el de " adoctrinamiento »-mejora al individuo que la practica. Pero más allá de los modelos ideológicos y conceptuales que, casi como un inventario de lugares comunes, enumera el texto, lo que se celebra aquí no son las virtudes edificantes de la lectura en el plano moral, sino sus virtudes creadoras en el plano de la escritura, es decir, la productividad de los modelos que, asimilados por el escritor mediante la lectura, lo guían a cada instante de su labor creadora. Reivindicando con fuerza la noción de modelo literario, el texto construye, en última instancia, una teoría de la intertextualidad ${ }^{7}$ que erige el acto de la lectura en acto de creación por excelencia.

En efecto, Quevedo o, más exactamente, la instancia a la que representa aquí el yo, aparece en el primer cuarteto no en calidad de escritor, sino en la de lector. Antes de afirmarse como autor de sus propios escritos (mis asuntos), se presenta como lector de los ajenos (los difuntos). Este desdoblamiento de la primera persona en instancia lectora y escritora se apoya, a su vez, en otra inversión, en virtud de la cual se le asigna al yo-lector del primer cuarteto un papel activo que se le rechaza al yo-escritor del segundo, donde se encuentra sintácticamente inmovilizado en posición de objeto. Declaran esta inversión las formas verbales de los cuartetos ; así, paradójicamente, el yo, que en la primera estrofa adopta la actitud más activa y dinámica frente a la lectura (vivo en conversación con los difuntos / y escucho con mis ojos a los muertos), asume en la siguiente la actitud más receptiva frente a la escritura ( $o$ enmiendan, o fecundan mis asuntos... / al sueño de la vida hablan despiertos). Si el primer cuarteto hace hincapié en la parte de actividad que encierra la lectura, no es sino para insistir con más fuerza, en el segundo, en lo que de pasivo hay en la escritura. Escribir es, a la vez que cumplir activamente el trabajo del que nacerá el texto, dejar que se cumpla pasivamente el trabajo de ensambla-

\footnotetext{
6. Emilio Carilla, «Quevedo y su soneto « Desde la torre ». (Un elogio hispánico de los libros) », Philologica hispaniensia in honorem Manuel Aloar, III, Madrid, Gredos, 1986, p. 47-60.

7. Aunque sólo hace una rápida alusión a este soneto, Lia Schwartz Lerner ha subrayado acertadamente la dimensión crítica y metatextual del soneto de Quevedo : "...el estudio de la intertextualidad [...] propone [...] descubrir, en el careo de cita y texto que la imita, las estructuras ideológicas que facilitaron la adopción y resemantización de ciertas fuentes. Quevedo nos ha dejado más de una indicación sobre el proceso de producción de sus enunciados. Pocas veces, con todo, lo hizo con tanto éxito como en el conocido soneto [ ¿ Desde la Torre "]. La lectura de sus textos predilectos no sólo enmendó o fecundó sus asuntos sino que determinó muchas veces la selección de una frase feliz y con ella toda una manera de construir el mundo elusivo que se resistía a la representación ", Queoedo : discurso y representación, Pamplona, EUNSA, 1986, p. 247-248.
} 
miento de todos los textos anteriormente leídos". " Crear - explica Didier Anzieu en un estudio ya clásico - no sólo es ponerse a trabajar. Es dejarse trabajar en el pensamiento [...] y en el cuerpo9 $"$.

El libro del soneto no representa, como se ve, el producto final de la escritura, es decir, la forma acabada de la creación, sino al contrario su punto de partida. El trabajo de creación se funda no en el acto de producción sino en el acto de recepción. El texto se nutre de otros textos; la lectura alimenta el quehacer del escritor : o enmiendan, o fecundan mis asuntos. Este verso, asociado al juego de oposiciones vivo / muerto del verso vivo en conversación con los difuntos, revela que, una vez leído, el texto, convertido en hipotexto, es susceptible de dirigir, en tanto que escritura remanente, el proceso de la creación $y$, por tanto, que ningún texto del pasado, actualizado, esto es, vivificado mediante la lectura, puede ser " letra muerta " en el proceso de producción de un nuevo texto. Si los escritos " permanecen " es también - transformados y reelaborados - a través de todos los textos que, reescribiéndolos, los resucitan ya sea en forma de reminiscencia, ya como cita indirecta, ya como imitación deliberada. El que la lectura esté asociada entonces a la audición - escucho con mis ojos a los muertos - no puede extrañar cuando se sabe que los ojos, asiento simbólico de la memoria como muestra la expresión tener grabado en la retina, son junto con el oído los dos sentidos principalmente implicados en los fenómenos de remanencia, esto es, de persistencia de una imagen (en este caso, la imagen del texto escrito) pasada la estimulación sensorial (en este caso, la lectura). Por eso, aunque la crítica haya subrayado el carácter sinestésico de la asociación escucho con mis ojos y aunque ésta se inscriba dentro de una larga tradición literaria ${ }^{10}$ - de Shakespeare"1 a Claudel, que afirmaba que el ojo escuchaba, y de Sor Juana Inés de la Cruz a Roland Barthes ${ }^{12}$, que decía ser víctima de una enfermedad que le condenaba a ver el lenguaje - no me parece necesario recurrir a esta figura ni a ningún otro tipo de desplazamiento metafórico para restituir la significación de este verso que, por lo demás, exige aquí una lectura rigurosamente literal ${ }^{13}$. La voz - y el empleo de este término en poética es en

8. A una forma análoga de medio-pasividad, si bien desde otra perspectiva y en otra área de estudio, se refiere Gustave Guillaume cuando explora, partiendo de su semiología pasiva, el semantismo supuestamente activo de los verbos deponentes latinos. Podría transponerse mutatis mutandis al ámbito de la creación literaria la sugerente lectura que éste propone del verbo loqui : « Un déponent comme loquor a sa cause dans ce que la parole a ses règles auxquelles le sujet obéit et, de plus, ses entraînements auxquels il c̀de. L'être agissant qu'est indubitablement celui qui parle se comporte, du fait qu'il suit les règles de la parole ou còde à ses entraînements, en être agi ". Langage et science du langage, Paris, Nizet, 1964.

9. Le corps de l'autre, Paris, Gallimard, 1981, p. 44. (La traducción es nuestra).

10. Cf. Charles Malamoud, « La voix et le sacré », Le grand atlas des litteratures, Paris, Universalis, 1990, p. 70.

11. E. Carilla cita en el mencionado estudio (p. 56) los versos del soneto XVIII de Shakespeare $* O$ learn to read what silent love hath wit, / To hear with eyes belongs to love's fine wit w.

12. * Je vois le langage *, Roland Barthes par Roland Barthes, Paris, Seuil, 1975, p. 164.

13. Sin renunciar por ello al concepto de sinestesia, E. Carilla ve aquí una alusión a la oralidad de la lectura : * Quevedo, hombre conocedor de la historia y los libros, parece evocar también, en su especial diallogo con los libros, el procedimiento de la lectura en voz alta, característico de los lectores de la antigüedad, y no desa parecido en la época de Quevedo », art. cit., p. 55. Por su parte, Nadine Ly me señala una correspondencia análoga en el romance Al nacimiento de Cristo Nuestro Serior de Góngora, en cuyo estribillo se hace equivaler el oer y el ofr, equivalencia amplificada en las primeras estrofas del 
sí mismo significativo - participa de ambos sentidos. Oír con los ojos corresponde exactamente a lo que hace el lector, que - a la escucha de lo que dice el texto - se adueña de él a medida que lo recorre con los ojos. Y es que los ojos son lo que, en última instancia, permite acceder no sólo a lo que comúnmente llamamos el sentido del texto, sino también a lo que Quevedo llama en el soneto músicos callados contrapuntos ${ }^{14}$, es decir : el ritmo. Efectivamente, y aunque la práctica no fuera ins6lita en el Siglo de Oro, no hay ninguna necesidad de leer un texto en voz alta para oírlo, como señala Henri Meschonnic para quien « el ritmo pone visión dentro de la audición ${ }^{15}$. El propio Ferdinand de Saussure, cuya teoría tergiversan aún quienes identifican el significante con la parte audible del signo, dejó bien sentado por su parte que la imagen acústica a la que llamaba significante no era el sonido sino su impronta psíquica, lo que argumentaba recordando que « sin mover los labios ni la lengua, podemos hablarnos a nosotros mismos y recitarnos mentalmente un poema ${ }^{16}$. No por ello, efectivamente, dejamos de oír las palabras...

Trabajado por todos los textos que ha leído, el escritor también lo está por los textos que él mismo ha producido. « Nunca escribo un poema [...] que no tenga en cuenta todos los poemas que he escrito anteriormente ni todos los poemas que he leído anteriormente ${ }^{17}$ ", decía Aragon reconociendo a la obra propia el mismo poder para guiarlo por los senderos de la creación que a la ajena. En efecto, la intertextualidad incluye también entre sus variantes la práctica de la auto-citación, desde su manifestación más trivial, el simple « tic de escritura » - que no es, en rigor, sino una forma de lexicalización idiolectal - hasta su expresión más incendiaria e iconoclasta, la palinodia, pasando por la « reutilización » o la « recuperación » textual de que hablaba François le Lyonnais cuando, a propósito de la literatura experimental, se dirigía al lector para preguntarle : " $i$ No ha tenido usted nunca, conmocionado ante un verso perfectamente logrado, la desoladora impresión de que es una pena que sólo haya servido una vez ? ¿ Agotará un buen verso toda su fuerza en un solo poema ${ }^{18}$ ? ". Así, en una de sus Epistolas a imitación de Séneca, recogida por Astrana Marín, Quevedo, reescribiendo el verso y escucho con mis ojos a los muertos y para evocar una vez más el comercio del poeta con los libros, dirá :

poema mediante la asociación de significantes luz-roz-paz : « ¿Quién oyó? / ¿ Quién oyó ? / ¿Quién ha visto lo que yo ? / Yacía la noche cuando / las doce a mis ojos dio [...] Una voz dieron los cielos, / Amor divino, / que era luz aunque era voz, / divino Amor. [...] Ruiseñor no era del Alba / dulce hijo el que se oyó ; / viste alas, mas no viste / vulto hu mano el ruiseñor... ". Agradezco asimismo a Aurora Egido la relación de fuentes que, a propósito de la asociación escucho con mis ojos, me comunica la autora y remito al lector interesado por la cuestión a su trabajo « Escritura y poesía. Lope al pie de la letra $*$, Edad de Oro, XIV, 1995, p. 121-149.

14. Sobre la asociación música / silencio puede consultarse el estudio de Aurora Egido « La poética del silencio en el Siglo de Oro », Fronteras de la poesía en el Barroco. Barcelona, Editorial Crítica, 1990, p. 56-84.

15. Critique du rythme, Paris, Verdier, 1982, p. 299. (La traducción es nuestra).

16. Cours de linguistique générale, Paris, Payot, 1985, p. 98.

17. Louis Aragon, Les yeuxd'Elsa, Paris, Grands Écrivains, 1984, p. 13-14. (La traducción es nuestra).

18. * A propos de la littérature expérimentale « (nota final a Cent Mille Milliards de Poèmes de Raymond Queneau), OULIPO, La litterature potentielle, Paris, Gallimard, 1973, p. 246. (La traducción es nuestra). 
...razonan conmigo los libros, cuyas palabras oigo con los ojos ${ }^{19}$.

Quevedo, sin embargo, ya había echado mano de esta feliz asociación de la vista y el oído en su Cuento de cuentos donde, desautomatizada por la escritura, aparece esta vez bajo un aspecto ridículo :

* Mire lo que digo * decimos todos por * óigame », pues no se parecen los ojos $y$ las orejas ${ }^{20}$.

$\mathrm{Si}$, como dice Barthes, " reescribirse » es « añadir a los libros, a los temas, a los recuerdos, otra enunciación ${ }^{21}$ ", es otra enunciación la que se le imprime aquí a la escritura, como también lo es la postura enunciativa que adopta Quevedo en el prólogo de su Cuento de cuentos desautomatizando sistemáticamente el lenguaje ${ }^{2}$ para poner de manifiesto las « incongruencias » del habla cotidiana - catacresis involuntarias, pleonasmos, oxímoros etimológicos, etc. - y tomando al pie de la letra expresiones figuradas, voces compuestas y frases hechas, procedimiento aquí puramente lúdico, pero que, cuando reviste implicaciones patológicas, refleja, por ejemplo en determinados casos de afasia, una incapacidad real por parte del hablante para desmotivar el lenguaje. Así, el paciente de que habla Fonágy ${ }^{23}$, que descompone la palabra chiendent como si ésta obedeciera a las leyes de la charada - esto es, como la suma de chien + dent - no somete el lenguaje a un tratamiento muy distinto al que lo someterá el propio Quevedo cuando escriba : "; Qué de hombres se hacen mogigatos, y nadie sabe qué son estos gatos mogi ${ }^{24}$ ! ". Pero el teorizador en que se convierte aquí Quevedo resulta mucho menos convincente que el poeta. Efectivamente, lo que sorprende aquí no es que el escritor haya ridiculizado el juego verbal de que se valdrá en el soneto y en la epístola citada, sino la justificación que aduce :...pues no se parecen los ojos y las orejas, como si los dos referentes en cuestión - y los dos nombres que los designan - fueran completamente ajenos entre sí. Cabe preguntarse si Quevedo no se habrá vuelto aquí súbitamente sordo al significante, hasta el punto de no percibir - de no oír - el vínculo analógico que hace de las orejas la forma amplificada y feminizada de los jos $^{25}$. Resulta difícil creerlo a la vista - y « al oído » - de

19. * 1941. Carta CCVIII. A persona desconocida \#, Epistolario completo de Don Francisco de Queoedo Villegas, Madrid, Instituto Editorial Reus, 1946, p. 421.

20. Obras festions (ed. de Pablo Jaraulde), Madrid, Castalia, 181, p. 151.

21. * Patch-work *, op. cit., p. 145. (La traducción es nuestra).

22. Véase a este respecto José María Pozuelo, El lenguaje poético de la lírica amorosa de Quevedo, Universidad de Murcia, 1979, p. 95-221.

23. « Motivation et remotivation. Comment se dépasser ? *, Poetique, num. 11, 1972, p. 415.

24. Ibid., p. 151.

25. Otro ejemplo - más sorprendente si cabe - de « sordera " al significante : la que translucen, paradójicamente, los ejemplos aducidos por Saussure para ilustrar, precisamente, la motivación del signo lingü istico : « ...pris séparément, "dix" et "neuf" sont sur le même pied que "vingt", mais "dixneuf" présente un cas de motivation relative. Il en est de même pour "poirier", qui rappelle le mot simple "poire" et dont le suffixe "-ier" fait penser à "cerisier", "pommier", etc. ; pour "frene", "chlne", etc. rien de semblable * (p. 181). ; Nada comparable ! ¿ Tan distintos le resultan frene y chene al lingüista como para no establecer, contrariamente al trio poirier-cerisier-pommier, ningún tipo de relación entre los dos significantes, que sólo se oponen gráficamente por las dos primeras letras ? Sin duda la demostración de Saussure hubiera resultado más convincente (aunque no por ello - y a pesar suyo más gráfica y reveladora del poder asociativo del signo) si, en vez de asociarlo al significante chene, hubiera pensado en oponer el significante frene al significante hetre,...a no ser que, como sospecho, éste 
versos como oigan lo que no ven mis enojos ${ }^{26}$ o sin ser oido y sin oír, ociosos / ojos y orejas, viviré olvidado ${ }^{27}$, que parecen dictados, consciente o inconscientemente, por la asociación semiótica que vincula a ambos significantes.

Restitución visual de la voz, la lectura - de la que el texto conserva, inscritas en callados contrapuntos, las « huellas mnésicas ${ }^{28}$ " - también está significada en el poema mediante el sustantivo conversación, que Quevedo prefirió a la palabra comercio empleada en una versión anterior del soneto ${ }^{29}$ y cuya etimologia comenta oportunamente Covarrubias :

CONVERSAR. [...] de con et versus, porque dice una razón y buélvenle otra, y de esta manera se trava la conversación.

La palabra conversación es, pues, una especie de oxímoron etimológico capaz de sugerir por sí mismo el doble movimiento de apropiación y de abolición del texto absorbido por la escritura, es decir, de identificación (con) y de oposición (versus) del hipertexto al hipotexto. De hecho, es lo que revela la semiología de la preposición contra, en cuyo significante puede leerse el de su antónimo con y que también aparece, empleada como prefijo, en la palabra contrapuntos, inicialmente incluída por el autor en el epígrafe del soneto, con vistas, probablemente, a hacer del enunciado comercio de difuntos contrapuntos el título del poema ${ }^{30}$. Así, si hubiera que transponer los conceptos a que remiten estos dos términos, diría que lo que Quevedo llama conversación corresponde a lo que Mikhail Bajtin, para definir el diálogo intertextual de que toda escritura

último me haya sido « dictado * aquí por una asociación tipográfica, inducida por la presencia de ese acento circunflejo que invariablemente remata la e que comparten los tres miembros de la serie dendronímica : frêne-chene-hetre...

26. Soneto 84.

27. Soneto 351.

28. Julia Kristéva, Enueıwııxn, Paris, Seuil, 1969, p. 74.

29. Se trata del texto autógrafo del Museo Británico 12108, reproducido por R. M. Price (op.cit., p. 95), que presenta numerosas variantes con respecto a la edición de Conzález de Salas : * Retirado en la paz de estos desiertos, / con pocos, pero doctos libros juntos, / vivo con el comercio de difuntos / y con mis ojos oigo hablar los muertos. / Si no siempre entendidos, siempre abiertos; / o enmiendan, o fecundan mis assumptos / los libros que, en callados contrapuntos, / al músico silencio estan despiertos. / Las grandes almas que la muerte ausenta, / de injurias de los años, vengadora, / restituie, D. Juan, docta la emprenta. / En fuga irrevocable huie la hora ; / mas con el mexor calculo se cuenta / la que en leccion $i$ estudio nos mexora *.

30. Manuscrito del Museo Británico 12108 (con múltiples correcciones hechas por Quevedo) recogido en James O. Crosby, En torno a la poesta de Quevedo, Madrid, Castalia, 1967, p. 16, 26 y 40 : « Retirado en la paz de estos desiertos. / [Joseph] em pocos, pero doctos libros juntos / bibo con el comerzio de difuntos. / i con mis ojos oigo hablar los muertos. / Si no siempre entendidos, siempre abiertos, / o [mexoran] o fecundan mis asumptos. / los libros, que en callados contrapuntos. / al musico silenzio estan despiertos. / Las grandes almas que la muerte [lleua,] [esconde] ausenta / [la emprenta a los estudios bienhechora] de injurias de los años, vengadora, / Irestituie, i en tinta las renueba] [restituie $i$ musica] restituie, d. Juan docta la emprenta / en fuga irrebocable huie la hora / mas [no tanto se ausenta inutil en quien zeba] con el mexor cálculo se cuenta / [la mente en la leccion que le mexora] [Quando] la que en leccion i estudio nos mexora ». 
es escenario, llamaba « dialogismo » y que el término musical contrapunto ${ }^{31}$ encuentra su correlato en el concepto bajtiniano de " polifonía ", acuñado por el formalista para designar la presencia concomitante de varias voces enunciativas dentro del mismo discurso ${ }^{32}$.

Teoría anticipada del dialogismo, el soneto explora, además, los mecanismos activadores del trabajo intertextual y los procesos por él desencadenados. En efecto, ni el escritor tiene necesariamente conciencia de este diálogo de textos ni controla siempre conscientemente la emergencia en su propio discurso de discursos ajenos al suyo, como parece indicar el verso si no siempre entendidos, siempre abiertos ${ }^{33}$. Hayan sido entendidos o no, los libros permanecen abiertos, es decir, siguen siendo productivos y siguen operando, después de la lectura, en tanto que imagen remanente de la escritura, ya que sus autores, como dice el soneto, al sueño de la vida hablan despiertos. Toda lectura es reescritura en potencia. Almacenados en la memoria consciente $o$ inconsciente del escritor, los fragmentos de escritura entretejen series asociativas cada uno de cuyos constituyentes libera a su vez nuevos paradigmas que se hacen, se deshacen y se rehacen a tenor de las analogías y oposiciones (fónicas, rítmicas, sintácticas) impuestas por los significantes ; dicho de otro modo, pasan a sumarse a todos los demás elementos del sistema, del fonema a la frase, y se integran en la trama asociativa que define el verdadero saber del escritor, para construir así la memoria de la « jugadas ya realizadas" en el lenguaje. Así, por ejemplo, todas las ediciones comentadas del soneto reproducen en nota a pie de página la cita de Séneca cum libellis mihi plurimus sermo est « converso abundantemente con los libros ", que ha podido dar pie, en tanto que matriz textual, a la composición de la primera estrofa. Ninguna de ellas señala, sin embargo, que la palabra libro, inducida en el discurso por el texto de Séneca, es a su vez inductora en el soneto de la palabra libra que viene a cerrar el paradigma de una especie

31. El término permite caracterizar asimismo la relación de negación instituida entre texto citante y texto citado. La definición que da de él el diccionario de Autoridades es singularmente escla recedora a este respecto : «...concordancia harmoniosa de vozes contrapuestas [...] Dicense contrapuestas, porque [...] se usan siempre yendo una voz contra otra, de suerte que si la voz baxa sube, la alta ha de baxar, y haciendo contrario movimiento la baxa, la alta ha de subir ".

32. Son éstos, precisamente, los dos términos que acuden a la pluma de José María Pozuelo cuando, a propósito del « Contexto de Quevedo » (Insula, núm. 558, 1993) y comentando el ensayo de Maxime Chevalier Quevedo y su tiempo : La agudeza verbal, comenta : « No hace mención Chevalier de la obra de Bajtin, ni la precisa, pero j qué bien podemos entender el concepto de dialogismo del teórico ruso o el de polifonía y de comunicación dialógica de discursos con la lectura de esta obra... ! * (p. 5).

33. La lectura anfibológica que de este verso propone Marie Roig (entendidos $=*$ comprendidos $»+$ * versados, doctos ") sólo es posible si se considera el adjetivo doctos del segundo verso como resultado de una enunciación irónica ; de otro modo, cuesta trabajo comprender por qué los mismos libros que Quevedo califica de doctos en la primera estrofa se califican en la segunda de no entendidos, esto es, de indoctos. "Entendidos signifie "compris" (par le poète), mais peut-être aussi "intelligents" si les livres sont personnifiés ; abiertos a un sens concret mais est peut-être aussi une correction du deuxième sens de entendidos : $s$ 'ils ne vont pas au fond des choses (par leur entendement), leur "ouverture d'esprit" peut permettre au poète de corriger, de nourrir sa propre réflexion. Ce deuxième sens ("même s"ils ne sont pas profonds, ils ouvrent toujours l'esprit") ne détruit pas le sens premier ("même si je ne les comprends pas toujours, je les consulte toujours") mais s'ajoute à lui, permettant une autre appréciation ", Les sonnets de Quevedo. Variations, constance, toolution, Presses Universitaires de Nancy, 1989, p. 167. 
de declinación, oponiendo quiásticamente el segmento doctos libros del primer cuarteto al segmento libra [...] docta del primer terceto. Cargada del recuerdo de otra escritura, la palabra libro está sometida aquí a una derivación paronímica, en que se confunde, bajo la apariencia de una banal flexión de género ${ }^{34}$, la genealogía de dos significantes etimológicamente inconexos : la del sustantivo libro y la del verbo librar ${ }^{35}$. Por medio de este juego, vemos funcionar, una como motor de otra, las dos modalidades extremas de la cita - desde su expresión mínima, el anagrama (o juego de letras), aquí materializado por la asociación libro / libra, hasta su manifestación más compleja, el paragrama (o juego de discurso), aquí representado por la cita de Séneca ${ }^{36}$-. El significante libro se sitúa de este modo en la intersección entre otros tres significantes que son : el sustantivo libellus del texto de Séneca, el sustantivo libros por el que ha sido traducido en el soneto y el verbo librar que la escritura poética hace derivar de él.

El trabajo asociativo - llámese etimológico, analógico, paronímico o derivativo - que dirige la escritura y del que el fenómeno intertextual no es, a mi modo de ver, sino la expresión sintáctica y macro-estructural, podría encontrar un interesante parangón para su estudio en el fenómeno que Roger Brown y David McNeil han llamado «The Tip of the Tongue phenomenon ${ }^{37}$ » y al que coloquialmente se alude por medio de la expresión « lo tengo en la punta de la lengua ». Roman Jakobson menciona también « ese estado en que el hablante no consigue acordarse de una palabra conocida, generalmente un nombre propio, pero que intenta reconstruir, ya sea asociándole palabras fonéticamente parecidas, ya sea improvisando una tras otra palabras que, inventadas para estimular la memoria, contienen elementos del nombre rastreado ${ }^{38}$ ". El hablante ve entonces desfilar en la memoria - y puede decirse también ante sus ojos - grafismos, sonoridades y ritmos, pero también fragmentos de discurso ya leídos, ya oídos o ya producidos y, más allá del lenguaje, formas, colores, situaciones, sensaciones. Este fenómeno, que puede compararse mutatis mutandis con los mecanimos asociativos movilizados en el proceso de la escritura, demuestra que si la búsqueda de una palabra puede ponerse en marcha a partir de un simple acento, de un simple fonema o de una simple estructura morfo-sintáctica es sencillamente porque el ritmo, la entonación, la sintaxis, etc. son estructuras desencadenantes capaces de

34. Atendiendo a la distribución en el texto de los morfemas de género, puede observarse que los cuartetos, sometidos al significante libros, están dominados por voces masculinas (retirado, estos desiertos, pocos, doctos libros juntos, los difuntos, ojos, los muertos, entendidos, abiertos, asuntos, músicos callados contrapuntos, sueño, despiertos), frente a los tercetos, que, sometidos al significante imprenta, presentan una clara mayoría de palabras femeninas (las grandes almas, la muerte, injurias, vengadora, docta la emprenta, fuga, la hora, aquella, la leccion).

35. Siguiendo a Francis Ponge, diremos : « Etymologistes, ne bondissez pas ! N'arrive-t-il pas que deux plantes aux racines fort distinctes confondent parfois leur feuillage ? Voilà de quoi il s'agit * ( Le porte-plume d'Alger \#, Methodes, Paris, Gallimard, 1961, p. 82).

36. Se han apuntado igualmente diversas fuentes posibles de la expresión el mejor calculo cuenta del antepenúltimo verso : Persio (« Hunc, Macrine, diem numera meliore lapillo \#, Satira II, v. 1) y Marcial ( $\propto$ diesque nobis / signandi melioribus lapillis ", Libro IX, epigrama LJI), entre otros (cf. John Conington, The Satires of A. Persius, Oxford, 1893, p. 34, nota a la sátira I, v. 1). Nótese, una vez más, que, siguiendo el modelo libros / libra, el significante * citado » mejor convoca en el verso siguiente al verbo mejora.

37. Journal of Verbal Learning and Verbal Behaviour, 5, 1966, p. 325-337.

38. La charpente phonique du langage, Paris, Minuit, 1980, p. 279. (La traducción es nuestra). 
funcionar como elementos inductores en el discurso. Del mismo modo que determinados rasgos (por ejemplo, la distribución silábica y acentual, el comienzo y el final de las palabras o la presencia de determinados fonemas ${ }^{39}$ ) se imponen con mayor fuerza a la retentiva que otros durante la búsqueda de la palabra, existen también en el texto leído - y, por tanto, archivado en la memoria - posiciones estratégicas y estructuras privilegiadas cuya impronta en el escrito puede activar la memoria diagramática y desencadenar la cita. El fenómeno brinda, en todo caso, valiosas informaciones tanto sobre las estructuras « que más poderosamente atraen nuestra atención en el estadio de la percepción ${ }^{40}$ " como sobre la configuración del diagrama (formado, como se ha dicho, por palabras, pero también por retazos de discurso), cuya movilización pone en juego una suma de competencias - lingüústica, literaria, ideologica - que determinan el saber del escritor, saber del que Francis Ponge ofrece una certera definición cuando escribe :

Mi libro tiene que sustituir : $1^{\circ}$ al diccionario enciclopédico, $2^{\circ}$ al diccionario etimológico, $3^{\circ}$ al diccionario analógico (no existe), $4^{\circ}$ al diccionario de rimas (de rimas internas igualmente), $5^{\circ}$ al diccionario de sinónimos, etc. $6^{\circ}$ a toda poesía lírica a partir de la Naturaleza, de objetos, etc..."

A modo de ejemplo, cabe mencionar el soneto de Quevedo Descripción del ardor canicular... que puede estudiarse íntegramente, a la luz que arrojan estos hechos, a partir del núcleo Ya la insana canícula [...] cuece las mieses, fiel traducción - como ya apuntó Dámaso Alonso ${ }^{42}$ - de los versos de Persio ...insana Canicula messes / iam dudum coquit $^{43}$ :

Ya la insana Canícula, ladrando llamas, cuece las mieses, y, en hervores de frenética luz, los labradores ven a Proción los campos abrasando.

El piélago encendido está exhalando al sol humos en traje de vapores ;

$y$, en el cuerpo, la sangre y los humores discurren sediciosos fulminando.

Bébese sin piedad la sed del día en las fuentes y arroyos, y en los rios la risa y el cristal y la armonía.

Ś́lo del llanto de los ojos míos no tiene el Can Mayor hidropesía, respetando el tributo a tus desvíos ${ }^{44}$.

39. Véase el estudio de Emilio Alarcos, « Expresividad fónica en la lírica de Quevedo \#, II Homenaje a Quevedo, Actas de la II Academia Literaria Renacentista, Universidad de Salamanca, 1982, p. 245-256.

40. R. Brown y D. McNeil, art cit., p. 325, citado por R. Jakobson, ibid., p. 279.

41. Le parti pris des choses, Paris, Seuil, 1988. (La traducción es nuestra).

42. Poesta española. Ensayo de métodos y límites estilisticos, Madrid, Gredos, 1976, p. 566-569.

43. Satiras, III, v. 5-6.

44. Edición de José Manuel Blecua, op. cit., p. 350. 
El análisis de este soneto, que no podré desarrollar aquí, pondría de manifiesto que, apenas citado, el modelo textual está reescrito y, por tanto, destruido por la escritura. Las cuatro palabras literalmente tomadas de la cita de Persio - insana, Canicula, cuece y mieses - aparecen inmediatamente retraducidas : así, el adjetivo insana se transforma en frenética, el significante Canícula, asociado al gerundio ladrando, se encuentra resemantizado con base en su propio étimo can, el verbo cocer convoca a la forma hervir y el sustantivo mieses llama al sustantivo campos, todo lo cual convierte el enunciado reconstruido *el frenético can hierve los campos en la versión quevediana de la insana Canícula cuece las mieses. Se pone de manifiesto entonces, partiendo de la frase de Persio, primero citada y transpuesta después, todo un trabajo asociativo y derivativo impuesto por los significantes elegidos en el incipit. El significante heroores va a convocar, por una parte, al sustantivo humos y, por otra, a su parónimo humores que se convierte así en una palabra sandwich, puesto que el significante humores aparece, tanto por su sentido como por su sonido, como la síntesis de humo + hervores. A su vez, la declinación antitética del radical hum -, asociado al fuego en un caso, humo, y a su contrario en el otro, humor, se resuelve en el significante fulminando, interpretado por González de Salas como sinónimo de ardiendo, pero en el-que parecen darse la mano dos parónimos y a la vez antónimos, a saber : fulmen " rayo » y flumen "río", como sugiere el verbo principal de la perífrasis discurren [...] fulminando y, más explícitamente aún, el verso en las fuentes y arroyos, $y$ en los ríos. Por último, el adjetivo sediciosos del verso discurren sediciosos fulminando más parece un derivado de sed que propiamente de sedición; en tódo caso, es lo que sugiere la configuración aliterada del verso Bébese sin piedad la sed del día, que incita a interpretar sediciosos como sinónimo de « muertos de sed ».

Si algo transluce de todo lo dicho es que la memoria del texto es indisociable de la de las palabras que lo construyen y es esta memoria la que protegen de las "injurias de los años " la invención de las letras - de que hablaría Nebrija ${ }^{45}$ - y la de la imprenta - a que Quevedo rinde aquí homenaje -. Cabe destacar, antes de concluir, la regresión que, subrayada por la derivación regresiva libro / libra, lleva dentro del soneto de la imagen del libro a la imagen de la imprenta, esto es, del producto a la producción o, si se prefiere, del resultado al proceso. Si en los dos cuartetos se valoran los doctos libros, los dos tercetos están dedicados a la docta emprenta. La irrupción en el texto de esta referencia a la cultura tipográfica modifica la posición ocupada hasta aquí por la palabra libro, estableciéndose así una correspondencia entre dos tipos de "impresion ${ }^{46}$ " diferentes, sensorial y memorial una (escucho con mis ojos), tipográfica otra (docta la emprenta), y convirtiendo la lectura en fundamento de la escritura. "Escribir»-dice Julia Kristeva - es « el leer

45. « La causa de la invención de las letras primera mente fue para nuestra memoria, y después, para que por ellas pudiéssemos hablar con los absentes y los que están por venir. Lo qual parece que ovo origen de aquello que ante que las letras fuessen halladas, por imágines representa van las cosas de que querian hazer memoria $"$, Gramatica de la lengua castellana, cap. III.

46. * IMPRESSIÓN. La señal que haze una cosa en otra [...] Sinifica también la esta mpa de los libros * (Covarrubias). 
hecho producción, industria ${ }^{47}$ " 0 , como dice Quevedo, « comercio ». Escritura y lectura participan de una misma práctica dialógica; y a ella permite precisamente hacer referencia aquí la imagen de la imprenta. En efecto, la imprenta, a medio camino entre la producción y la recepción textual, efectúa la simbiosis de la lectura y de la escritura, y evoca al mismo tiempo que la imagen del texto imprimido en la hoja blanca, la del texto que, imprimiéndose en la memoria del lector, quedará sobreimpreso en su propia escritura, es decir la imagen de la huella sensible dejada por el texto "leído " en el texto " escrito ".

"Hablo palabras con barriga, preñadas ${ }^{48}$ ", escribió una vez Quevedo, consciente del poder asociativo y rememorativo de las palabras, moldeadas por la escritura en instrumento de la memoria y prenadas del recuerdo de todos los libros leídos. Y si el poeta dice aquí no tener más compañía que la que le proporcionaban unos pocos, pero doctos libros, sabemos hasta qué punto, aunque la bibliotecta particular de Quevedo no alcanzara los cinco mil volúmenes que consignó Tarsia $^{49} \mathrm{en}$ su biografía, estaba aquejado de esa "dolencia " que, en otro soneto y para poner en solfa a coleccionistas de libros, bulímicos de la lectura y demás bibliófagos, bautizó con el sugerente nombre de libropesía. En estas condiciones no puede sorprender que el autor haya puesto en consonancia aquí su labor creadora con su experiencia como lector, relacionando la escritura con la práctica misma de que se nutre : la lectura. Si escribir es volver a escribir lo ya leído, las notas marginales y apostillas hechas por el propio Quevedo en los libros que leía demuestran que la palabra « reescritura " no tiene aquí nada de metafórico. Lector activo, Quevedo no se conformaba con corregir erratas, subrayar palabras o hacer observaciones personales - con singular frecuencia observaciones de orden formal ${ }^{50}$, , sino que, como ha dejado patente el estudio de algunos de los libros que manejó y que le pertenecieron, como su ejemplar de la Eracleida ${ }^{51}$ de Zinano, tachaba y suprimía vocablos, sustituía por otras, palabras y expresiones enteras, modificaba el texto a su antojo ${ }^{52}$ convirtiéndolo en un pre-texto para el ejercicio literario, en una palabra : reescribía los libros a medida que los leía, haciendo que, de alguna manera, se cumpliese así el

47. Op. cit., p. 120.

48. « Palabras preñadas, las que contienen virtualmente mucho más de lo que espressan * (Covarrubias). Frase citada par Lázaro Carreter (“Quevedo : la invención por la palabra », II Homenaje a Quecedo, Actas de la II Academia Literaria Renacentista, Universidad de Salamanca, 1982, p. 13), quien la toma de la * Carta XII. Al duque de Osuna. 1615 " (Obras completas en prose, Madrid, Aguilar, 1945, p. 1603).

49. « Vida de don Francisco de Quevedo * (incluida en la edición de Astrana Marín, Obras completas. Obras en verso, Madrid, Aguilar, 1943, p. 749). Véase Felipe C.R. Maldonado * Algunos datos sobre la composición y dispersión de la biblioteca de Quevedo , Homenaje a la memoria de D. Antonio Rodriguez Moñino, Madrid, Castalia, 1975, p. 405-428.

50. Véanse, por ejemplo, la apostillas de Quevedo a los poemas de Herrera.

51. Ejemplar estudiado por Michèle Gendreau en "Quevedo lecteur de l'Eracleide de Gabriele Zinano ", MAanges offerts a Charles Vincent Aubrun, I, Paris, Editions hispaniques, 1975, p. 313-320. Lo mismo puede decirse de su ejemplar del Epttome de Floro, estudiado por Henry Ettinghaussen, "Quevedo marginalia : his copy of Floru's Epitome \#, Modern Language Reciew, 1964, LIX, p. 391-398.

52. Tarsia (op. cit., p. 750) comentaba : « Leíalos no de paso, sino margenándolos con apuntar lo más notable y con añadir, donde le parecía, su censura *. 
mito de la lectura y de la escritura simultáneas ${ }^{53}$. Frente al libro escrito, lo que reivindica Quevedo en su soneto es el libro que escribe y es esta concepción del libro no como producto, sino como productividad la que, además de fecundar su escritura, nutre aquí la reflexión del escritor.

53. Uno de los últimos avatares de este mito lo representa Silas Flannery, el personaje de f́talo Calvino (Si una noche de invierno un viajero...) que se convierte en copista para * vivir * a la vez en el tiempo de la escritura y en el de la lectura. 